\title{
Susceptibility to antifungal drugs of Candida albicans isolated from upper respiratory tract of patients with chronic hepatitis C
}

\author{
Anna Biernasiuk', Anna Malm', Sławomir Kiciak², Krzysztof Tomasiewicz \\ ${ }^{1}$ Department of Pharmaceutical Microbiology, Medical University, Lublin, Poland \\ ${ }^{2}$ Department of Infectious Diseases, Medical University, Lublin, Poland
}

Biernasiuk Anna, Malm Anna, Kiciak Sławomir, Tomasiewicz K. Susceptibility to antifungal drugs of Candida albicans isolated from upper respiratory tract of patients with chronic hepatitis C. J Pre-Clin Clin Res. 2013; 7(2): 111-113.

\begin{abstract}
Introduction. Patients with chronic HCV infection due to itheir mmunocompromised status are predisposed to opportunistic infections caused by microorganisms of normal microflora, e.g. fungal infections caused especially by yeast species belonging to Candida spp., mainly Candida albicans.

Objective. The aim of this study was to analyze the drug susceptibility of Candida albicans colonizing the upper respiratory tract isolated from 100 patients with chronic hepatitis C from group I (without antiviral therapy) and from group II (treated with peginterferon and ribavirin).

Material and Methods. The 30 isolates of C. albicans from group I and 31 isolates from group II were identified by standard methods - biochemical microtest API 20 C AUX (bioMérieux). The drug sensitivity to antifungal drugs (amphotericin B, flucytosine, fluconazole, itraconazole, ketoconazole and miconazole) was estimated by the Fungitest method (Sanofi Diagnostics Pasteur).

Results. Among the isolates of $C$. albicans, $100 \%$ sensitivity to flucytosine and amphotericin B was found, irrespective of the patient group. However, a decreased sensitivity to azole derivates - miconazole, ketoconazole, itraconazole or fluconazole was noted, amounting to $3.33-56.67 \%$ in the isolates from group I, while in group II amounting $9.68-48.39 \%$, depending on the antifungal drugs. The isolates resistant to ketoconazole (6.67\%) or itraconazole (10\%) were found in group I, while resistant to miconazole (9.68\%), ketoconazole (19.35\%), itraconazole (22.58\%) or fluconazole (3.22\%) in group II.

Conclusion. Determination of drug sensitivity of the isolated yeast species should be the basis of rational and successful therapy.
\end{abstract}

\section{Key words}

chronic hepatitis C, Candida albicans, drug susceptibility, upper respiratory tract

\section{INTRODUCTION}

Hepatitis $C$ infection is an infection of the liver caused by the hepatitis $\mathrm{C}$ virus (HCV). HCV can cause acute or chronic hepatitis and is a health problem worldwide. It is one of the leading causes of cirrhosis and hepatocellular carcinoma and is a common indication for liver transplantation $[1,2,3$, $4,5,6]$. Therapy is based on markers that predict sustained virologic response, and the goal of therapy is to slow or to halt progression of fibrosis and prevent the development of cirrhosis. In future, multidrug regimens in combination with current therapies may be developed. A combination of pegylated interferon (peginterferon) alpha weekly and ribavirin daily represents the standard for the treatment of chronic hepatitis $\mathrm{C}$ according to current guidelines. In some cases, boceprevir or telaprevir may be included $[1,7$, $8,9,10,11]$.

Patients with chronic HCV infection due to their immunocompromised status are predisposed to opportunistic infections caused by microorganisms of normal microflora, e.g. fungal infections caused especially by yeast species belonging to Candida spp., mainly Candida albicans. Among them, the most common are respiratory

Address for correspondence: Anna Biernasiuk, Department of Pharmaceutical Microbiology, Medical University, Lublin, Poland

e-mail: ania.biernasiuk@umlub.pl

Received: 01 August 2013; accepted: 02 February 2014 tract candidiasis which are usually of endogenous in origin due to colonization of nasopharyngeal mucosa by Candida spp. Increasing diversity among species of pathogenic yeast fungi in respiratory tract infections and their resistance to antifungal agents may contribute to therapeutic failures. The determination in vitro of susceptibility to drugs of Candida spp. is often used to select antifungal agents likely to be clinically active for a given infection $[7,12]$.

The aim of the presented study was to evaluate the drug susceptibility of C. albicans colonizing the upper respiratory tract in patients with chronic hepatitis $\mathrm{C}$, with or without standard antiviral therapy, including peginterferon and ribavirin. The susceptibility to selected antifungal drugs: flucytosine (analogue pyrimidine), amphotericin B (polyene antibiotic), miconazole and ketoconazole (imidazole derivatives), itraconazole and fluconazole (triazole derivatives) of 61 C. albicans isolates was estimated using the Fungitest.

\section{MATERIALS AND METHOD}

Swabs from the oral cavity and mucous membrane of throat and nose were obtained from 100 patients aged $30-65$ years with chronic hepatitis $\mathrm{C}$, belonging to 2 groups: group I - 46 patients without antiviral therapy and group II - 54 patients treated with peginterferon and ribavirin. None of 
the patients had lesions in the oral cavity. Samples were taken with a sterile cotton swabs and immediately streaked onto Sabouraud agar with chloramphenicol. The 30 isolates of C. albicans from group I and 31 from group II were identified by standard methods - biochemical microtest API $20 \mathrm{C}$ AUX (bioMérieux) on the basis of assimilation of various substrates.

The drug sensitivity was estimated by the Fungitest method (Sanofi Diagnostics Pasteur). This is a microplatebased procedure for the breakpoint testing of 6 antifungal drugs (amphotericin B, flucytosine, fluconazole, itraconazole, ketoconazole and miconazole). Each 16-well microplate contains 2 negative control wells, 2 positive growth control wells, and 12 drug-containing wells. Each antifungal agent was tested at 2 concentrations, selected to distinguish resistant isolates from susceptible ones. The drug concentrations were as follows: amphotericin B -2 and $8 \mu \mathrm{g} / \mathrm{ml}$; flucytosine -2 and $32 \mu \mathrm{g} / \mathrm{ml}$; fluconazole -8 and $64 \mu \mathrm{g} / \mathrm{ml}$; itraconazole and ketoconazole -0.5 and $4 \mu \mathrm{g} / \mathrm{ml}$; and miconazole -0.5 and $8 \mu \mathrm{g} / \mathrm{ml}$. Cell suspensions were prepared in sterile distilled water and were adjusted to a turbidity corresponding to a 1.0 McFarland standard; $100 \mu \mathrm{l}$ of this suspension was added to $1.9 \mathrm{ml}$ of sterile distilled water, and this was further diluted by adding $20 \mu \mathrm{l}$ to $3 \mathrm{ml}$ of pre-prepared RPMI 1640 suspension medium. This gave a final inoculum concentration of $10^{3} \mathrm{CFU}$ (Colony Forming Units)/ml. The microplates were inoculated by placing $100 \mu \mathrm{l}$ of the appropriate cell suspension into each well. The plates were incubated at $37^{\circ} \mathrm{C}$ for $48 \mathrm{~h}$ before reading. Two reference strains, C. albicans ATCC 2091, C. albicans ATCC 10231 and C. parapsilosis ATCC 22019, were included in each batch of broth microdilution tests to ensure quality control.

\section{RESULTS}

The prevalence of Candida spp. in throat or/and oral cavity was found in $20(43.48 \%)$ and $24(44.44 \%)$ patients with HCV from group I and II, respectively. The predominant species was Candida albicans identified in $20(43.48 \%)$ patients of group I and 22 (40.74\%) patients of group II.

On analysing the sensitivity of C. albicans isolates from the group I of patients (Tab. 1), it was found that the isolates were sensitive in $100 \%$ to flucytosine and polyene antibiotic - amphotericin B, but had decreased sensitivity, so-called sensitivity dose-dependent, to azole derivates - miconazole $(16.67 \%)$, ketoconazole $(10 \%)$, itraconazole $(56.67 \%)$ or fluconazole (3.33\%). The isolates resistant to azole derivates were found to be resistant to ketoconazole (6.67\%) or itraconazole (10\%). Moreover, 1 (3.33\%) isolate possessed decreased sensitivity or resistance to all tested azoles.

Analysis of the sensitivity of C. albicans isolates from group II of patients (Tab. 2), 100\% sensitivity to flucytosine and polyene antibiotic - amphotericin B was also found. A decreased sensitivity to miconazole, ketoconazole, itraconazole and fluconazole was observed, amounting $19.35 \%, 19.35 \%, 48.39 \%, 9.68 \%$ of the isolates, respectively. In turn, the isolates were observed to be resistant to miconazole (9.68\%), ketoconazole (19.35\%), itraconazole $(22.58 \%)$ or fluconazole (3.22\%). In addition, 3 (9.68\%) isolates showed decreased sensitivity or resistance to all tested azoles.
Table 1. Sensitivity to antifungal drugs of Candida albicans isolated from the upper respiratory tract of patients with chronic hepatitis $C$ from group I without antiviral therapy

\begin{tabular}{llcl}
\hline Antifungal drug & \multicolumn{3}{c}{ No. (percentage) of isolates } \\
\cline { 2 - 4 } & Resistant & $\begin{array}{c}\text { Sensitive dose- } \\
\text { dependent }\end{array}$ & Sensitive \\
\hline Flucytosine & $0(0)$ & $0(0)$ & $30(100)$ \\
\hline Amphotericin B & $0(0)$ & $0(0)$ & $30(100)$ \\
\hline Miconazole & $0(0)$ & $5(16.67)$ & $25(83.33)$ \\
\hline Ketoconazole & $2(6.67)$ & $3(10)$ & $25(83.33)$ \\
\hline Itraconazole & $3(10)$ & $17(56.67)$ & $10(33.33)$ \\
\hline Fluconazole & $0(0)$ & $1(3.33)$ & $29(96.67)$ \\
\hline
\end{tabular}

Table 2. Sensitivity to antifungal drugs of Candida albicans isolated from the upper respiratory tract of patients with chronic hepatitis $C$ from group Il with antiviral therapy

\begin{tabular}{llcc}
\hline Antifungal drug & \multicolumn{3}{c}{ No. (percentage) of isolates } \\
\cline { 2 - 4 } & Resistant & $\begin{array}{c}\text { Sensitive dose- } \\
\text { dependent }\end{array}$ & Sensitive \\
\hline Flucytosine & $0(0)$ & $0(0)$ & $31(100)$ \\
\hline Amphotericin B & $0(0)$ & $0(0)$ & $31(100)$ \\
\hline Miconazole & $3(9.68)$ & $6(19.35)$ & $22(70.97)$ \\
\hline Ketoconazole & $6(19.35)$ & $6(19.35)$ & $19(61.30)$ \\
\hline Itraconazole & $7(22.58)$ & $15(48.39)$ & $9(29.03)$ \\
\hline Fluconazole & $1(3.22)$ & $3(9.68)$ & $27(87.10)$ \\
\hline
\end{tabular}

\section{DISCUSSION}

Fungal infections are an important medical problem in patients from risk groups, among them in patients with chronic hepatitis $\mathrm{C}$. Increased frequency of fungal infections in recent years is associated with inappropriate use of antifungal drugs. This is a major cause for the emergence of resistant or multi-drug resistant strains, which may lead to many therapeutic failures $[1,8,12]$.

The prevalence of Candida spp. in the upper respiratory tract of patients with chronic hepatitis $\mathrm{C}$ from both groups without or with the standard antiviral therapy (peginterferon and ribavirin), ranging from $43.48-44.44 \%$, was similar to that found in healthy people $[7,13,14]$. Similarly, other authors [15] showed that cultures of Candida sp. from the tongue surfaces were positive in $50 \%$ patients with $\mathrm{HCV}$ infection at least once during therapy with interferon. The incidence of Candida spp. in these patients during interferon treatment did not increase, compared to that before treatment.

Data presented in this study showed that all of the C. albicans strains colonizing upper respiratory tract of patients with chronic hepatitis $C$ from the both groups were sensitive in $100 \%$ to amphotericin B and flucytosine, which is in agreement with data obtained by other authors [7, 12, $16,17]$. The high sensitivities to both the antifungal drugs were observed, by Oberoi J. K. et al. [5], amounting 89.6\% and $90.9 \%$ of the studied isolates, respectively, and by KrajewskaKułak E. et al. [16] amounting $84.2-91.5 \%$ and $87.7-93.6-\%$ of the isolates studied, respectively.

Recently, the decreased susceptibility of Candida spp., including $C$. albicans to azole derivatives, has been increasing $[5,12,17,19]$. The data in the presented study are in agreement 
with this tendency, showing the decreased susceptibility to azole derivatives, in the case of itraconazole reaching even $56.67 \%$ and $48.39 \%$ of C. albicans isolates. Similar results have been obtained by other authors for C. albicans isolated from the oral cavity in patients with HIV/AIDS, from the upper respiratory tract of patients with lung cancer, from blood specimens or from neoplasmatic patients $[12,15,17$, $18]$. According to other literature data $[5,19]$, the decreased sensitivity to fluconazole was found with a frequency amount of $6-31.2 \%$, while to itraconazole with a frequency of $14-45.7 \%$.

The results from group I in the presented study confirm that isolates were resistant to ketoconazole and itraconazole in $6.67 \%$ and $10 \%$, respectively. In turn, in group II there appeared resistance to fluconazole $(3.22 \%)$, miconazole (9.68\%), and significantly often, resistance to ketoconazole (19.35\%) and itraconazole (22.58\%). Data presented in this paper and those from literature indicate that the successful treatment of candidiasis by azoles has been also been impaired by the emergence of drug-resistant strains. Mulu A. et al. [18] also found that Candida spp. isolated from oropharyngeal candidiasis from patients with HIV/AIDS were resistant to fluconazole (12.2\%), ketoconazole (7.7\%) and itraconazole (4.7\%). The results of studies by Zomorodian K. et al. [17] demonstrated that among the clinical isolates of C. albicans the resistance to ketoconazole was found to be $3.2 \%$. JinSol L. et al. [19] assessed that resistance to fluconazole and itraconazole was found in $2 \%$ and $4 \%$ of the bloodstream Candida isolates, respectively. In turn, Pfaller at al. [6] showed that among the clinical isolates of Candida spp., 3.96\% were resistant to fluconazole and up to $71 \%$ of those were resistant to itraconazole.

Data presented in this study and those from the literature strongly indicate that the increasing rate of resistance to azoles among Candida spp., including C. albicans isolates, has become a major problem, especially among immunocompromised patients, in which these drugs, mainly fluconazole, are usually used in prophylaxis of fungal infections $[4,7,9,12,19]$.

\section{CONCLUSIONS}

Actual knowledge about the drug sensitivity of Candida spp. including C. albicans isolated from the upper respiratory tract, allow its proposal as successful prophylaxis and treatment of potential respiratory tract infections caused by pathogenic yeasts in a given population, including patients with HCV.

\section{REFERENCES}

1. Awad T, Thorlund K, Hauser G, Stimac D, Mabrouk M, Gluud C. Peginterferon alpha-2a is associated with higher sustained virological response than peginterferon alfa-2b in chronic hepatitis C: systematic review of randomized trials. Hepatology 2010; 51(4): 1176-84.
2. Graham CS, Wells A, Liu T, Sherman KE, Peters M, Chung RT, Bhan AK, Andersen J, Koziel MJ, ACTG 5071 Study Team. Antigenspecific immune responses and liver histology in HIV and hepatitis C coinfection. AIDS 2005; 19(8): 767-73.

3. Graham CS, Wells A, Liu T, Sherman KE, Peters M, Chung RT, Bhan AK, Andersen J, Koziel MJ, ACTG 5071 Study Team. Relationships between cellular immune responses and treatment outcomes with interferon and ribavirin in HIV/hepatitis $\mathrm{C}$ virus co-infection. AIDS 2006; 20(3): 345-51.

4. Moreno A, Cervera C, Fortún J, Blanes M, Montejo E, Abradelo M, Len O, Rafecas A, Martín-Davila P, Torre-Cisneros J, Salcedo M, Cordero E, Lozano R, Pérez I, Rimola A, Miró JM. OLT-HIV FIPSE cohort investigators. Epidemiology and outcome of infections in human immunodeficiency virus/hepatitis $\mathrm{C}$ virus-coinfected liver transplant recipients: a FIPSE/GESIDA prospective cohort study. Liver Transpl. 2012; 18(1): 70-81.

5. Oberoi JK, Wattal C, Goel N, Raveendran R, Datta S, Prasad K. Nonalbicans Candida species in blood stream infections in a tertiary care hospital at New Delhi, India. Indian J Med Res. 2012; 136(6): 997-1003.

6. Pfaller MA, Diekema DJ, Messer SA, Hollis RJ, Jones RN. In vitro activities of caspofungin compared with those of fluconazole and itraconazole against 3,959 clinical isolates of Candida spp., including 157 fluconazole-resistant isolates. Antimicrob Agents Chemother 2003; 47(3): 1068-1071.

7. Biernasiuk A, Mahorowska-Kiciak I, Grzegorczyk A, Malm A. In vitro susceptibility of pharyngeal isolates of Candida albicans to some antifungal drugs. Ann UMCS. 2006; 61(2): 802-805.

8. Chien RN, Yang LJ, Lin PY, Liaw YF. Hepatic injury during ketoconazole therapy in patients with onychomycosis: a controlled cohort study. Hepatology 1997; 25(1): 103-7.

9. Paya CV. Prevention of fungal and hepatitis virus infections in liver transplantation. Clin Infect Dis. 2001, 1: 47-52.

10. Sulka A, Simon K, Piszko P, Kalecińska E, Dominiak M. Oral mucosa alterations in chronic hepatitis and cirrhosis due to $\mathrm{HBV}$ or $\mathrm{HCV}$ infection. Bull Group Int Rech Sci Stomatol Odontol. 2006; 47(1): 6-10.

11. Wilkins T, Malcolm JK, Raina D, Schade RR. Hepatitis C: diagnosis and treatment. Am Fam Physician. 2010; 81(11): 1351-7.

12. Biernasiuk A, Korona-Głowniak I, Mahorowska-Kiciak I, Rybojad P, Malm A. Pharyngeal Candida spp. strains in patients with non-small cell lung cancer. Mikol Lek. 2006; 13(2): 89-93.

13. Grossmann SM, Teixeira R, de Aguiar MC, de Moura MD, do Carmo MA. Oral mucosal conditions in chronic hepatitis $\mathrm{C}$ Brazilian patients: a cross-sectional study. J Public Health Dent. 2009; 69(3): 168-75.

14. Williams DW, Lewis MAO. Isolation and identification of Candida from the oral cavity. Oral Dis. 2000; 6(1): 3-11.

15. Nagao Y, Hashimoto K, Sata M. Candidiasis and other oral mucosal lesions during and after interferon therapy for HCV-related chronic liver diseases. BMC Gastroenterol. 2012; 2(12): 155.

16. Krajewska-Kułak E, Niczyporuk W, Łukaszuk C, Krawczuk-Rybak M, Wojtukiewicz M, Kułak W, Sobaniec H. Usefulness of Fungitest in the estimation of susceptibility of the yeast-like fungi to antifungal in cancer patients. Mikol Lek. 1999; 6(4): 213-219.

17.Zomorodian K, Rahimi MJ, Kayvan P, Motamedi MMR, Hasanein R. Determination of antifungal susceptibility patterns among the clinical isolates of Candida species. J Glob Infect Dis. 2011; 3(4): 357-360.

18. Mulu A, Kassu A, Anagaw B, Moges B, Gelaw A, Alemayehu M, Belyhun Y, Biadglegne F, Hurissa Z, Moges F, Isogai E. Frequent detection of azole resistant Candida species among late presenting AIDS patients in northwest Ethiopia. BMC Infect Dis. 2013; 13(1): 82.

19. Jin-Sol L, Jong HS, Kyungwon L, Mi-Na K, Bo-Moon S, Young U, WeeGyo L, Hye SL, Chulhun LCh, Soo HK, Myung GS, Soon PS, Dong WR. Species distribution and susceptibility to azole antifungals of Candida bloodstream isolates from eight university hospitals in Korea. Yonsei Med J. 2007; 48(5): 779-786. 